\title{
LA REPRESIÓN EN LA GUERRA CIVIL: ÚLTIMAS APORTACIONES BIBLIOGRÁFICAS Y MOVIMIENTOS SOCIALES POR LA MEMORIA
}

Julián Chaves Palacios

\section{INTRODUCCIÓN}

Tras superar el año 2006, doblemente conmemorativo por celebrar los setenta y cinco años del nacimiento de la Segunda República y los setenta del estallido de la Guerra Civil, resulta cuanto menos pertinente efectuar una radiografía sobre las publicaciones aparecidas en los últimos tiempos sobre el enfrentamiento armado que asoló el territorio español entre 1936-1939 y, más exactamente, sobre la cuestión más controvertida de esa contienda: la represión. Estamos convencidos que su estudio, pese a los avances registrados en los últimos decenios, es uno de los temas pendientes en la comprensión de ese conflicto, no sólo por lo que supone conocer su alcance y consecuencias en ambos bandos, sino también por sus indudables efectos en cuanto a conseguir ese objetivo que debe constituir una tarea común de todos los españoles: la reconciliación.

$Y$ es que ese entendimiento, tan demandado por la sociedad española, no puede tener lugar mientras los dos grandes bloques políticos que protagonizaron ese enfrentamiento armado, derecha e izquierda, no reconozcan y condenen los crímenes y errores que sus antecesores cometieron en esos años. Y, evidentemente, en esa línea de reconocimiento, qué duda cabe que la derecha, entendida de una forma global, tiene que efectuar mayores muestras de contrición sobre su pasado, pues propició la insurrección de julio de 1936, protagonizó la represión desde un primer momento y, tras finalizar la guerra, lejos de fomentar la reconciliación fomentó todo lo contrario: la arbitrariedad y el terror.

A veces cuesta llamar a las cosas por su verdadero nombre, máxime cuando hacemos referencia a un conflicto de estas características en que ambos bandos perpetraron acciones represivas, pero ello no debe oscurecer el análisis y la reflexión: el alcance de las actividades represivas perpetradas por los republicanos 
son conocidas desde los años cuarenta del pasado siglo (Causa General), mientras que las originadas por los franquistas en pleno siglo XXI estamos tratando de saber su verdadera dimensión. Una diferencia, pues, fundamental, a la que se une la falta de información veraz sobre los atropellos cometidos. De ahí la importancia del historiador en este proceso, que en España se ha denominado, con mayor o menor acierto, de "recuperación de la memoria histórica", que está permitiendo importantes avances sobre las atrocidades represivas practicadas por el franquismo.

Implicación de las instituciones que ha tenido como resultado llevar al Parlamento español, en el año 2006, la "Ley de reconocimiento y extensión de los derechos a las víctimas de la guerra civil y la dictadura", que está siendo debatida por los grupos parlamentarios. Un texto legal denostado por la derecha (abrir heridas) y criticado por la izquierda más radical (demasiado corto en sus objetivos), que consideramos afronta cuestiones pendientes como un reconocimiento general que «proclame la injusticia de las condenas, sanciones y cualquier forma de violencia producida por razones políticas o ideológicas durante la Guerra Civil»; reparaciones a los perjudicados; pensiones y compensaciones económicas a los hijos de fusilados y fallecidos en la contienda; afrontar la retirada de símbolos que exalten a uno u otro bando; $y$, finalmente, abordar el lacerante asunto de las fosas comunes de republicanos fusilados por el bando franquista y acabar, de forma concluyente, con el tremendo lastre que supone tener salpicada la geografía española de esos «agujeros negros».

Cuestiones, pues, que confirman la necesidad de que nuestro Parlamento ratifique una Ley de estas características, que todos los grupos políticos se esfuercen en llegar a un acuerdo que permita su aprobación con el mayor consenso político posible. Un consenso en materia tan sensible de nuestra historia que consideramos pertinente y necesario con vistas a lograr esa reconciliación tan deseable. Estamos convencidos que su aprobación supondrá la rehabilitación oficial, en nombre del Estado, de todas las víctimas de la Guerra Civil y la represión posterior. Toda una novedad en la España democrática actual, que permitirá llevar a cabo actuaciones que lejos de reabrir viejas heridas estamos convencidos que ayudará a cicatrizarlas, superando la división del pasado y consolidando la convivencia entre los españoles.

$Y$ en ese contexto entendemos que los estudios sobre las consecuencias represivas de la Guerra Civil adquieren una relevancia especial, entre otras razones porque permitirán la identificación de las víctimas, especialmente aquellas que fueron pasadas por las armas por el bando de Franco durante la contienda y en la posguerra que son las más desconocidas en cuanto a su número e identidad. Datos, por poner un ejemplo, como la identificación del fusilado y el lugar de ejecución y posible enterramiento serán fundamentales para llevar a cabo acciones de exhumación de fosas tan demandados por los familiares de los afectados. Utilidad e implicación social que debe ser asumida por el historiador, no sólo para divulgar sus investigaciones, sino también para dar respuesta a lo que la sociedad le demanda en este sentido. Estamos convencidos de ello, como también de que los historiadores, a tenor del repertorio bibliográfico que 
iremos desgranando en este estudio, están a la altura que requieren las circunstancias actuales.

\section{MEMORIA DE LA REPRESIÓN EN DEMOCRACIA}

Como es de dominio público, la mayor parte de los estudios realizados sobre la Guerra Civil hasta la muerte del dictador tuvieron un carácter general, escasamente apoyados en los fondos documentales accesibles, y marcados, en cuanto al tratamiento de determinados temas, por las circunstancias políticas vigentes, que no permitían encarar con garantías el tratamiento de facetas como la represiva. La historiografía sobre el conflicto se vio sumida en un fuerte anquilosamiento, convirtiéndose la precariedad metodológica e interpretativa en una constante. La instrumentalización del estudio al servicio de planteamientos ideológicos fue la norma. Para los defensores del régimen de Franco se trataba tanto de salvar responsabilidades por el comienzo del conflicto, atribuyendo su origen a una conspiración comunista, como de ocultar situaciones y comportamientos, tergiversando el sentido del desarrollo histórico. Más que obras de historia, muchas veces fueron panfletos de tipo apologético que conformaban una amplia literatura de la justificación ${ }^{1}$.

Trabajos en que la falta de rigor y objetividad se convirtieron en una constante, con una deliberada deformación de los hechos que se hacía especialmente llamativa cuando el objeto de estudio era una materia tan sensible y objeto de manipulación como la represión ${ }^{2}$. Su estudio en este período, por lo general, fue ajeno a cualquier atisbo de rigor, con la ocultación y negación de la parte de responsabilidad inherente a un conflicto de estas características, y su utilización, sin embargo, como elemento propagandístico, con la publicación de informes tan explícitos, en cuanto a denunciar la actividad represiva republicana, como la Causa General, avalado por el mismo Ministerio de Justicia ${ }^{3}$. Esa situación fue variando con la paulatina consolidación de un sistema democrático en el país. A ello colaboró de una forma efectiva el acceso de los investigadores a fondos archivísticos hasta entonces vedados, en los que se podía encontrar una información novedosa, variada y de distinta procedencia.

Un importante paso, sin duda, independientemente del estado en que se encontraba esa documentación y de las lagunas que ofrecía como consecuencia del deliberado expolio a que había sido objeto ${ }^{4}$. Pero contingencias aparte, lo

1. Véase sobre esta argumentación, SOUthworth, H., El mito de la Cruzada de Franco, París, Ruedo Ibérico, 1963.

2. SÁNCHEZ RECIO, G., "Presupuestos teóricos y metodológicos del concepto de represión», en CHAVES, J. (coord.), Memoria Histórica y guerra Civil: Represión en Extremadura, Badajoz, Diputación Provincial, 2004, pp. 21-38.

3. Véase DiRECCIÓN GENERAL De INFORMACIÓN, La dominación roja en España. Causa General instruida por el Ministerio Fiscal, Madrid, Publicaciones Españolas, 1961.

4. Sobre esto último reseñar, a título de ejemplo, cómo en el año 1976, siguiendo instrucciones expresas del entonces Ministerio de Gobernación, que tenía como responsable de esa cartera a Rodolfo Martín Villa, se ordenó centralizar en la capital de España la documentación existente en los cuarteles de la Guardia Civil sobre el conflicto armado de 1936-1939 y el franquismo. "Mi- 
cierto es que por primera vez desde la finalización de la Guerra Civil se permitía a los investigadores acceder a archivos y documentos sobre ese período histórico hasta entonces no consultados, proceso que se consolidó en los años de democracia. Años en los que no sólo cabe destacar los fondos documentales procedentes de archivos oficiales, sino también los de origen privado, siendo preciso resaltar en ese sentido la labor desarrollada por las fundaciones.

En concreto, desde los inicios de la Transición comenzaron a constituirse en España instituciones sin fines de lucro, amparadas en el artículo 34 de la Constitución de 1978, en el que se contempla el derecho a la creación de establecimientos "para fines de interés general». Ello dio lugar a la aparición de fundaciones tan importantes para el estudio de los últimos setenta años de la Historia de España, como Pablo Iglesias, Indalecio Prieto, Investigaciones Marxistas o Francisco Franco. El acceso a esta última ${ }^{5}$, a diferencia de las restantes, ha sido limitado y eso ha motivado que durante años haya sido objeto de críticas por parte de los investigadores, entre otras razones por encontrarse en manos privadas el archivo de un Jefe de Estado. Sin embargo, al parecer gracias a la concesión de unas subvenciones millonarias no exentas de polémica ${ }^{6}$, esa situación ha cambiado sustancialmente: su acceso no es tan limitado y se tiene prácticamente digitalizada toda la documentación para ser consultada.

Pero hasta que llegó ese acceso a los archivos tras la muerte del dictador y la eclosión posterior de publicaciones novedosas y documentadas, merecen especial mención las aportaciones de hispanistas franceses y británicos, que no eran españoles ni fueron combatientes en la Guerra Civil, y que introdujeron en sus trabajos sobre el conflicto armado interpretaciones alejadas de la hagiografía imperante en la España de Franco, con obras de conjunto serias y documentadas que adquirieron amplia difusión. Aunque hubo excepciones como el estudio de Gerald Brenan que se publicó poco después de finalizada la Guerra Civil ${ }^{7}$, fue a partir de los años sesenta cuando comenzaron a aparecer estos trabajos pioneros en contenido y tratamiento ${ }^{8}$, que posteriormente, especialmente en los años de la Transición, van a conocer nuevas ediciones, revisadas y actualizadas, de acuerdo con las últimas investigaciones. Fue el caso, por citar algunos ejemplos,

les de documentos llegaron a las manos de una "comisión histórica» que como principal objetivo debía construir la versión de la Guardia Civil que podría soportar la democracia. Montañas de documentos fueron destruidos entre los años 1976 y 1978 entre los que se encontraban numerosas informaciones acerca de personas desaparecidas durante la guerra y posguerra». SILVA, E. y MACÍAS, S., Las fosas de Franco. Los republicanos que el dictador dejó en las cunetas, Madrid, Temas de Hoy, 2003, p. 120.

5. La Fundación Francisco Franco fue creada en junio de 1977 por iniciativa de 227 personas de la vida pública de esos años (en la actualidad ha alcanzado alrededor de los 3.000 socios), y tiene un archivo de casi treinta mil documentos sobre la dictadura franquista.

6. Véase GALÁN, L., "Memoria enfrentada», El País, 11-I-2004.

7. Brenan, G., El Laberinto español. Antecedentes sociales y políticos de la guerra civil, París, Ruedo Ibérico, 1962. En inglés, la primera edición data de 1943.

8. Entre los trabajos publicados en los años sesenta cabe citar, además de los que mencionaremos con posterioridad, el ya citado de SOUTHWORTH, H. R., El mito... y el de PAYNE, S. G., Los militares y la política en la España contemporánea, París, Ruedo Ibérico, 1968. 
de las obras realizadas por los hispanistas anglosajones Hugh Thomas ${ }^{9}$, I. Gibson $^{10}$, Gabriel Jackson ${ }^{11}$, o los franceses Pierre Broué y Emile Témime ${ }^{12}$.

Con el progresivo asentamiento democrático en el país se produjo una auténtica eclosión de estudios sobre la Guerra Civil, hasta el punto que en el decenio de los ochenta se registró el mayor número de publicaciones sobre la contienda del último cuarto del siglo $\mathrm{XX}^{13}$. Razones como la celebración del cincuentenario de su inicio (1986) y conclusión (1989) coadyuvaron de forma decidida a esa vorágine editorial. Y junto a esas efemérides y actividades afines cabe destacar la tendencia «revisionista» que se fue imponiendo sobre este conflicto armado, iniciada tras la Transición y que en los años ochenta adquirió un nuevo y renovador enfoque que se concretó, de forma muy especial, en la búsqueda de nuevas perspectivas espaciales que vinieron a complementar y enriquecer las obras de carácter general. Las monografías provinciales y regionales pasaron a ser las protagonistas, de forma que la paulatina aparición en el mercado editorial de estos trabajos de contenido marcadamente territorial completó una de las carencias existentes en el panorama historiográfico sobre la Guerra Civil.

En estas publicaciones es preciso destacar que el análisis de la represión se convirtió en tema predilecto. Faceta "delicada» de tratar por sus evidentes implicaciones políticas -la actuación violenta sobre las personas y las cosas-, se puede afirmar que su estudio estaba aún pendiente de realizar, al menos desde un prisma realmente histórico, acorde con las exigencias básicas de la actual historiografía. Poco se sabía de los efectos represivos en un plano regional, más allá de algunos trabajos locales escasamente representativos, haciéndose necesario emprender su investigación desde ese criterio territorial. En ese sentido colaboraba la situación política del país, con un desarrollo democrático que distaba mucho de etapas pretéritas -franquismo-, donde era impensable abordar con garantías suficientes el tratamiento de facetas como las muertes violentas originadas durante el conflicto ${ }^{14}$.

Y dentro del análisis de la represión, una de las cuestiones determinantes en su estudio ha sido establecer balances sobre las muertes ocasionadas por uno

9. The Spanish Civil War, Londres, Eyre and Spottiswoode, 1961. Al año siguiente vio su primera edición en castellano, siendo publicado en París por Ediciones Ruedo Ibérico. Y en 1978, la editorial Grijalbo volvía a editarlo en dos volúmenes, en lo que era su cuarta edición, corregida y aumentada

10. Granada en 1936 y el asesinato de Federico García Lorca, Barcelona, Crítica, 1975.

11. La República española y la guerra civil 1931-1939, México, Ed. Americana, 1967. Esta obra, revisada, fue reeditada por la Editorial Crítica, en 1976.

12. La revolución y la guerra de España, Madrid, Fondo de Cultura Económica, 1977, 2 vols. Este trabajo ya había sido publicado en París, Éditions Minuit, con el título La Revolution et la Guerre d'Espagne.

13. RUIZ FRANCO, M. ${ }^{a}$ R. y RiesCo ROCHE, S., "Veinte años de producción histórica sobre la Guerra Civil española (1975-1985): Una aproximación bibliométrica», Revista Española de Documentación Científica, vol. 22, n. ${ }^{\circ} 2$ (1999), p. 183.

14. Una obra pionera sobre esta faceta, no exenta de interés, aunque insuficiente, fue la de VILLAR SALINAS, J., Repercusiones demográficas de la última guerra civil española. Problemas que plantean y soluciones posibles, Madrid, Sobrinos de la Sucesora de M. Minuesa de los Ríos, 1942. 
y otro bando durante la contienda. Y en esas investigaciones sobre las cifras de óbitos, la publicación de referencia, por ser la primera en estudiar sistemáticamente sus efectos en toda la geografía española, considerando éstos dentro del cómputo global de las pérdidas demográficas totales ocasionadas por la guerra, fue la de Ramón Salas Larrazábal ${ }^{15}$. Un trabajo publicado a finales de los años setenta y basado en las cifras estadísticas oficiales que, a lo largo de los ochenta, quedó en entredicho ante las relevantes aportaciones de los estudios territoriales que se fueron publicando a partir de esa década ${ }^{16}$, que mostraban de forma fehaciente la insuficiencia de fuentes como el Instituto Nacional de Estadística para el estudio de la represión.

Una de esas primeras publicaciones de ámbito regional fue, en 1982, la de A. Hernández García y G. Herrero Balsa sobre la provincia de Soria ${ }^{17}$, y, dos años más tarde, la del primero de ellos sobre La Rioja ${ }^{18}$. En ambas se ponía de manifiesto la necesidad de revisar al alza las cifras ofrecidas por Salas Larrazábal, especialmente las referidas a la represión provocada por el bando franquista ${ }^{19}$. Era un primer aviso que publicaciones posteriores no hicieron más que confirmar. Ese mismo año, 1984, se publicaba un nuevo libro, en este caso referido a una provincia andaluza, concretamente el del profesor A. Nadal sobre Málaga, ${ }^{20}$ con una estimación de 7.000 muertes, mientras que Salas sólo contabilizaba 3.864. También se publicó otro sobre Oviedo ${ }^{21}$ y Extremadura ${ }^{22}$.

Ya en 1985, continuando con los estudios regionales y el análisis que en éstos se realiza sobre la represión y sus $\operatorname{cifras}^{23}$, se público otro trabajo provincial, que a las fuentes habituales para el estudio de la guerra añadía el protagonismo concedido en sus páginas a la historia oral. Nos estamos refiriendo al trabajo

15. Salas Larrazábal, R., Pérdidas de la guerra, Barcelona, Planeta, 1977.

16. Véase una síntesis sobre las discrepancias entre las cifras ofrecidas por Salas y estos trabajos territoriales, en MORENO GÓMEZ, F. y otros, "La represión, la tragedia oculta», La aventura de la Historia, n. ${ }^{\circ}$ 3, enero 1999, pp. 11-33.

17. BALSA, G., y HeRnÁndeZ, A., La represión en Soria durante la Guerra Civil, Soria, Edic. Autores, 1982, 2 vols.

18. HeRnÁNDEZ, A., La represión en La Rioja durante la Guerra Civil, Logroño, el autor, 1984, 2 vols.

19. En el estudio sobre Soria, se relacionan con nombre y apellidos las 281 víctimas de la represión franquista, mientras que Salas sólo contabiliza 82. Y en el caso de La Rioja, A. Hernández sumaba 2.000 muertes, lo que suponía, al igual que el caso anterior, más del doble de las ofrecidas por Salas -un total de 912 defunciones-.

20. NADAL, A., Guerra Civil en Málaga, Málaga, Arguval, 1984.

21. En este caso fue realizado por la Asociación de Viudas de los Defensores de la República y del Frente Popular de Asturias, Fosa común del cementerio de Oviedo, Oviedo, 1984, trabajo que completaron después con otro: Represión de los tribunales militares franquistas en Oviedo, fosa común del cementerio civil de Oviedo, Oviedo, 1988.

22. VILA, J., Extremadura: la Guerra Civil, Badajoz, Universitas Editorial, 1984. Y de este mismo autor, dos años después, véase La guerrilla antifranquista en Extremadura, Badajoz, Universitas Editorial, 1986. En ninguno de los dos trabajos se ofrecen cifras de víctimas, tratándose de visiones generales, marcadas por un claro matiz militante.

23. También se realizaron estudios locales, como fue el caso de Canarias. Véase CABRERA ACOSTA, M. A., La represión franquista en el Hierro (1936-1944), Santa Cruz de Tenerife, Tagoror de Ediciones, 1985. 
realizado por F. Moreno Gómez sobre Córdoba ${ }^{24}$, en el que de nuevo se ponían en evidencia las cifras de Salas, en este caso con un desajuste que superaba el doble de óbitos de los registrados por éste en toda la provincia, a causa de los fusilamientos llevado a cabo por el bando de Franco. Diferencia que se invertía, siempre según lo estudiado por este autor, al ofrecer los datos de la represión republicana, donde el cómputo de Salas era ligeramente mayor al ofrecido por F. Moreno ${ }^{25}$.

Sin embargo, esa línea de discrepancia no fue tan significativa para el caso catalán. Nos estamos refiriendo a la obra de J. M. Solé acerca de Cataluña ${ }^{26}$, publicada en 1985, que salvo los datos sobre Gerona, en el resto no había tanta diferencia con los ofrecidos por Salas. Algo similar podemos decir del trabajo de R. Quirosa, en este caso editado en 1986 y dedicado a Almería ${ }^{27}$. Criterio que no puede aplicarse en otro libro editado ese mismo año sobre Navarra, realizado por el colectivo Altaffaylla Kultur Taldea ${ }^{28}$, que tras efectuar un pormenorizado estudio en cada pueblo, donde consultaron archivos y entrevistaron a numerosas personas que vivieron aquellos hechos, pusieron en cuestión las cifras de Ramón Salas, con un balance de muertes superior al doble de las ofrecidas por aquél.

En suma, la carencia de estudios territoriales sobre la guerra se fue paliando, poco a poco, con la publicación de trabajos como los citados. Trabajos que pese a la carga de localismo que se aprecia en sus páginas, sin olvidar el sesgo ideológico y reivindicativo que algunos autores han dado a su contenido, han supuesto un importante revulsivo en las investigaciones sobre el conflicto armado de 1936-1939. La renovación interpretativa y documental que se aprecia en sus páginas constituyó una experiencia con resultados bastante satisfactorios, al haber acrecentado, de forma más concreta y precisa, el conocimiento de los hechos acaecidos durante el conflicto en determinadas zonas de España, que las obras generales difícilmente podían abordar.

Aspectos concretos tratados en estos libros, como la decisiva temática represiva, siempre compleja y difícil de cuantificar, se ve necesitada de este tipo de publicaciones para conocerla en su conjunto. Es indispensable su existencia para poder dar luz a una de las cuestiones pendientes de la Guerra Civil, que poco a poco se va desgranando gracias a las aportaciones bibliográficas regionales,

24. Moreno, A., La Guerra Civil en Córdoba (1936-1939), Madrid, Alpuerto, 1985. Y dos años después este mismo autor publicó Córdoba en la posguerra (la represión y la guerrilla, 1939-1950), Córdoba, Francisco Baena, 1987.

25. En cuanto a la represión franquista en Córdoba, las cifras de F. Moreno arrojan un balance de 9.579 muertes, mientras que las de Salas 3.864. Y en la republicana 2.384 defunciones para el primer caso y 2.642 en el otro.

26. SOlÉ I SABATÉ, J. M., La repressió franquista a Catalunya (1938-1953), Barcelona, Edicions 62, 1985. Años después este mismo autor, junto a VillarROYA, J., La repressió a la retaguarda de Catalunya, Barcelona, Abadía de Montserrat, 1990, 2 vols.

27. Para este autor, la represión practicada por el bando de Franco alcanzó las 373 defunciones, y según Salas un total de 386. Existe mayor disparidad en la republicana, donde Quirosa indica 471 óbitos y Salas 985. Véase Quirosa, R., Politica y guerra civil en Almería, Almería, Cajal, 1986.

28. AltafFaylla Kultur Taldea, Navarra 1936. De la esperanza al terror, Pamplona, el autor, 1986, 2 vols. 
una vez demostrado que las obras de síntesis sobre esta materia -caso de Salas Larrazábal- presentan carencias en las cifras difícilmente asumibles.

De hecho, y en consonancia con esa necesidad, a lo largo de la década de los noventa este tipo de investigaciones ha ocupado lugar preferente en los estudios sobre la contienda. Los libros sobre la guerra de ámbito regional han seguido proliferando, y poco a poco se han ido extendiendo a buena parte de la geografía española. En ese sentido cabe citar las publicaciones relacionadas con Comunidades Autónomas como la de Andalucía ${ }^{29}$, Extremadura ${ }^{30}$ Aragón $^{31}$, Asturias ${ }^{32}$, Canarias ${ }^{33}$, Castilla-La Mancha ${ }^{34}$, Murcia $^{35}$, Madrid $^{36}$, Baleares ${ }^{37}$, País Vasco ${ }^{38}$ y Valencia ${ }^{39}$.

29. Véase sobre esta Comunidad, Braojos Garrido, A., ÁlVarez Rey, L. y Espinosa Maestre, F., Sevilla 36: sublevación fascista y represión, Sevilla, Muñoz y Montraveta Editores, 1990; SALAS, N., Sevilla fue la clave: república, Alzamiento, guerra civil (1931-1939), Sevilla, Castillejo, 1992; СОВО ROMERO, F., La guerra civil y la represión franquista en la provincia de Jaén (1936-1950), Jaén, Diputación Provincial, 1993; EsPinOSA MAESTRE, F., La guerra civil en Huelva, Huelva, Diputación Provincial, 1996; Gil Bracero, R., Granada: jaque a la República, Granada, Caja General de Ahorros de Granada, 1998; ORTIZ VILLALBA, J., Sevilla: del golpe militar a la guerra civil, Córdoba, Imprenta Vistalegre, 1998; СОВO ROMERO, F., Conflicto rural y violencia política. El largo camino hacia la dictadura, Jaén: 1917-1950, Jaén, Universidad de Jaén, 1998.

30. SÁNCHEZ MARroYo, F., "La Guerra Civil en Extremadura. Estado de la cuestión", Investigaciones Históricas, n. 9 (1989), pp. 139-160; GALlardo MORENO, J., La guerra civil en La Serena, Badajoz, Diputación Provincial, 1994; MARTín RuBio, A. D., La represión roja en Badajoz, Oviedo, T.A.R.F.E., 1994; ChAVES PALACIOS, J., La represión en la provincia de Cáceres durante la guerra civil, 1936-1939, Cáceres, Universidad de Extremadura, 1995; Chaves PALACiOs, J., La guerra civil en Extremadura. Operaciones militares (1936-1939), Mérida, Junta de Extremadura, 1997.

31. CaSAnOVA, J. y otros, El pasado oculto. Fascismo y violencia en Aragón (1936-1939), Madrid, Siglo XXI, 1992; Cifuentes ChueCA, J. y MALUENDA PONS, P., El asalto a la República. Los orígenes del franquismo en Zaragoza (1936-1939), Zaragoza, Institución Fernando el Católico, 1995; y CENARRO LAGUNAS, A., El fin de la esperanza: fascismo y guerra civil en la provincia de Teruel (1936-1939), Teruel, Diputación Provincial, 1996.

32. Ortega VAlCÁrcel, M. ${ }^{a}$ E., La represión en Asturias. Ejecutados y fallecidos en la cárcel del Coto de Gijón, Avilés, Azucel, 1994.

33. GARCÍA LUIS, R., La justicia de los rebeldes: los fusilados en Santa Cruz de Tenerife (1936-1940), Santa Cruz de Tenerife, Tegueste, 1994.

34. Referido a Toledo, véase SABín, J. M., Prisión y muerte en la España de postguerra, Madrid, AnayaMario Muchnik, 1990. Y sobre otras provincias de esta Comunidad, BERMúDEZ, A., República y guerra civil. Manzanares (1931-1939), Ciudad Real, Diputación de Ciudad Real, 1992; AlíA MiRAnDA, F., La guerra civil en retaguardia. Conflicto y revolución en la provincia de Ciudad Real (1936-1939), Ciudad Real, Diputación Provincial, 1994; OrTIZ HerAS, M., Violencia política en la II República y el primer franquismo. Albacete: 1936-1950, Madrid, Siglo XXI, 1996.

35. Egea BRuno, P. M., La represión franquista en Cartagena (1939-1945), Murcia, PCPE, 1987; y GONZÁlez MARTíneZ, C., Guerra Civil en Murcia. Un análisis sobre el poder y los comportamientos colectivos, Murcia, Universidad de Murcia, 1999.

36. NúÑEz-BALART, M. y ROJAS, A., Consejo de guerra. Los fusilamientos en el Madrid de la posguerra (1939-1945), Madrid, La Compañía Literaria, 1998; CerVERA, J., Madrid en guerra. La ciudad clandestina: 1936-1939, Madrid, Alianza, 1998.

37. Ginard i FERON, D., El moviment obrer de Mallorca i la Guerra Civil (1936-1939), Barcelona, Publicaciones de l'Abadia de Montserrat, 1999.

38. Alonso CARballés, J. J., 1937: los niños vascos evacuados a Francia y Bélgica, Bilbao, Asociación de niños evacuados del 37, 1998.

39. Gabarda Cebellán, V., Els afusellaments al País Valencià (1938-1956), Valencia, Ed. Alfons el Magnànim, 1993; ORS MONTENEGRO, M., La represión de guerra y posguerra en Alicante (1936- 
Esas obras regionales, aunque importantes en su número y aportaciones, sin embargo no han sido suficientes para ofrecer un balance global de lo sucedido en toda España. Así al menos se desprende de la obra de síntesis sobre «víctimas de la guerra", coordinada por Santos Juliá ${ }^{40}$ y publicada en 1999 , en la que sus autores efectúan un recorrido sobre la actividad represiva practicada por uno y otro bando tanto en la contienda como en la posguerra. Parten del mismo concepto de víctimas de la Guerra Civil, que definen como «muertos de forma violenta que no lo hayan sido en acciones de guerra», es decir, estudian los paseos y muertes incontroladas, y con ese fin exponen un relato que abarca la cronología total de los hechos en toda su extensión geográfica "resumiendo en una síntesis general todo lo investigado hasta el momento presente».

Un esfuerzo significativo, que no ha sido el único pues también otros historiadores como el sacerdote A. D. Martín Rubio, sobre cuya obra volveremos más adelante, lo han realizado, aunque con distinto planteamiento y resulta$\mathrm{dos}^{41}$. En todo caso se trataba de ofrecer obras de conjunto que compendien todo lo monográfico y local publicado sobre esa materia en las diferentes regiones españolas hasta finales de siglo, que pusieran de manifiesto los avances conseguidos y aquello que aún quedaba por hacer. Y es que, especialmente en lo concerniente al alcance de la represión, esos trabajos ponían de manifiesto lagunas que debían ser afrontadas con posterioridad, como se ha demostrado en las publicaciones que sobre esa materia han ido apareciendo en los primeros años del nuevo milenio.

\section{NUEVO MILENIO: A VUELTAS CON LA GUERRA CIVIL}

Investigaciones que han confirmado esa línea de análisis territorial por ser la que mejores resultados está proporcionando en cuanto al estudio del alcance del fenómeno represivo, especialmente aquel de mayor alcance en cuanto a cifra de fusilados: el franquista. Y es que el "problema de las cifras», aunque con estas aportaciones regionales, y otras que se han publicado en los últimos años, se ha avanzado bastante, los datos existentes resultan aún insuficientes. Así, pese a que el mapa no se puede dar por definitivamente cerrado, a la vista de los trabajos citados y los que analizaremos a continuación, podemos avanzar una cifra de víctimas a causa de la represión en la guerra civil y posguerra en toda España que alcanza a unas 200.000 personas, de las que 150.000 corresponden

1945), Alicante, Instituto de Cultura Juan Gil-Albert, 1995; y GABARDA CEBELLÁN, V., La represión en la retaguardia republicana. País Valenciano, 1936-1939, Valencia, Ed. Alfons el Magnànim, 1996.

40. Juliá, S. (coord.); Casanova, J.; Solé y Sabaté, J. M.; Villarroya, J. y Moreno, F., Víctimas de la guerra civil, Madrid, Temas de Hoy, 1999.

41. Parte de cifras oficiales (INE) y cuestiona los resultados de determinadas investigaciones territoriales. Véase Rubio MarTín, A. D., Paz, piedad y perdón... y verdad, Madrid, Fénix, 1997. 
a represaliados por el bando franquista y el resto al republicano ${ }^{42}$. Cantidades que, insistimos, no son concluyentes aunque consideramos que están próximas a los dígitos definitivos de óbitos que por prácticas represivas originó el conflicto armado de 1936-1939 en todo el país.

El ingente número de trabajos publicados en lo que llevamos de nuevo siglo, más de cuatrocientos libros ${ }^{43}$, muestra la creciente demanda historiográfica de este período de la Historia de España, del interés que suscita su análisis entre los historiadores, pero también del escenario en que se ha convertido su estudio para fomentar visiones encontradas, que llevan el debate político e ideológico al análisis histórico y lejos de aportar nuevos conocimientos ha enrarecido considerablemente la investigación sobre la contienda. Destacamos en ese sentido, dentro de lo que se ha dado en llamar "revisionismo neofranquista», los trabajos realizados por P. $\mathrm{Moa}^{44}$, C. Vidal ${ }^{45}$ y el ya citado A. D. Martín.

Sobre este último cabe decir, pues los otros están suficientemente publicitados y estamos convencidos que incidir en sus trabajos lejos de la saludable crítica historiográfica sólo origina una mayor venta de libros por su parte, que sus investigaciones sobre la Guerra Civil se iniciaron a mediados de los noventa del pasado siglo y estuvieron dedicadas al análisis de la represión republicana en la provincia de Badajoz ${ }^{46}$. Posteriormente sus estudios han tenido un contenido más general, con una clara predisposición a mostrar las bondades de los sublevados durante la guerra ${ }^{47}$, en detrimento de la actuación de los republicanos $^{48}$. Posicionamiento historiográfico en absoluto novedoso ${ }^{49}$, pero que en los últimos tiempos ha adquirido una especial resonancia dado el grupo de autores que la respaldan y, sobre todo, la aceptación que algunos de ellos han tenido entre los lectores, con un elevado número de venta de sus libros.

Evidentemente esa deriva interpretativa ha tenido contestación por parte de diversos historiadores ${ }^{50}$, incluso con alusiones claras en el título de sus obras a algunos de los autores ubicados en esa vertiente "neofranquista» ${ }^{51}$, en los que

42. SÁNCHEZ MARROYO, F., «Represión franquista y represión republicana en la Guerra Civil», en Chaves, J., Memoria Histórica y Guerra Civil: Represión en Extremadura, Badajoz, Diputación Provincial, pp. 39-60 (p. 49 para esta cita).

43. Blanco RodrígueZ, J. A., "La historiografía de la Guerra Civil española», Hispania Nova. Revista de Historia Contemporánea, n. ${ }^{\circ} 7$ (2007), pp. 1-33 (p. 33 para esta cita).

44. Los mitos de la guerra civil, Madrid, La Esfera Libros, 2003 y Los crimenes de la guerra civil y otras polémicas, Madrid, Esfera Libros, 2004.

45. Checas de Madrid, Barcelona, Belacqua, 2003.

46. MARTín, A. D., La represión roja en Badajoz, Oviedo, T.A.R.F.E., 1994 y La persecución religiosa en Extremadura durante la guerra civil (1936-1939), Badajoz, Fondo de Estudios Sociales, 1999.

47. Salvar la memoria. Una reflexión sobre las víctimas de la guerra civil, Badajoz, Fondo de Estudios Sociales, 1999.

48. Los mitos de la represión en la guerra civil, Madrid, Grafite Ediciones, 2005.

49. Las obras de Ricardo de la Cierva han sido pioneras en esa tendencia historiográfica proclive a la causa representada por los sublevados.

50. MORADIELLOS, E., "La intervención extranjera en la guerra civil: un ejercicio de crítica historiográfica", Ayer, 50 (2003), pp. 199-234. También de este mismo autor, 1936. Los mitos de la guerra civil, Barcelona, Península, 2004.

51. ReIG TAPIA, A., Anti-Moa, Barcelona, Ediciones B, 2006. 
inciden en la fragilidad de sus argumentos y la tendenciosidad de sus análisis. Incluso esas críticas han merecido opúsculos como el realizado por Francisco Espinosa, El fenómeno revisionista o los fantasmas de la derecha española (Badajoz, Los libros del Oeste, 2005), que se han centrado, entre otros aspectos, en cuestionar las interpretaciones efectuadas por P. Moa y A. D. Martín en relación a un espacio territorial concreto: Badajoz. Sus trabajos sobre esa provincia ${ }^{52}$, le sirven de justificación para poner en entredicho las tesis ofrecidas por esos autores acerca de la despiadada represión que sufrieron los vecinos de esa ciudad extremeña, tras su ocupación, el 14 de agosto de 1936, por las tropas franquistas al mando del teniente coronel Yagüe.

Estudios, en definitiva, que tratan de desmontar, con mayor o menor fortuna, lo realizado por esos investigadores "neofranquistas», que a su vez no le han dolido prendas en rebatir esos planteamientos ${ }^{53}$. En suma, un rifirrafe poco edificante, que pone de manifiesto, pese a que se van a cumplir ya casi setenta años desde su conclusión, las controversias que origina en la actualidad la Guerra Civil, y especialmente su contenido más controvertido y polémico: la represión. Se impone, pues, la historia con mayúsculas, y consideramos que los trabajos que se vienen realizando en los últimos años sobre la represión durante la contienda armada de 1936-1939 y con posterioridad, tanto en un plano nacional ${ }^{54}$ como territorial, acallan esas obras que cuestionan los hechos, los reinterpretan y ofrecen unas conclusiones que a nuestro modesto saber y entender se alejan del quehacer histórico.

Entre esas obras de contenido más general cabe destacar el estudio de variables como el análisis de la Administración de Justicia en ambas zonas en conflicto, con aportaciones tan sugerentes como la realizada por Raúl C. Cancio Fernández ${ }^{55}$, en que estudia su funcionamiento y, lo que es más importante, la instrumentalización que ambos bandos realizaron de los tribunales como herramienta bélica. Del mismo modo los centros de reclusión han merecido en los últimos años la atención de los historiadores ${ }^{56}$, con enfoques globales sobre el universo carcelario franquista en España de indudable interés ${ }^{57}$. También aspectos más concretos como los centros concentracionarios que se extendieron por toda la geografía española en la guerra y posguerra ${ }^{58}$,

52. Espinosa MAestre, F., La columna de la muerte, Barcelona, Crítica, 2003.

53. MOA, P., Los crimenes de la guerra civil y otras polémicas, Madrid, La Esfera de los Libros, 2004.

54. Molinero, C., "¿Memoria de la represión o memoria del franquismo?», en Juliá, S., (dir.), Memoria de la guerra y del franquismo, Madrid, Taurus, 2006, pp. 219-246.

55. Guerra Civil y Tribunales: de los Jurados populares a la justicia franquista (1936-1939), Cáceres, Universidad de Extremadura, 2007.

56. Chaves Palacios, J., «Franquismo: prisiones y prisioneros», Pasado y Memoria. Revista de Historia Contemporánea, 4 (2005), pp. 27-48.

57. Molinero, C., SAlA, M. y SOBReQués, J. (eds.), Una inmensa prisión: los campos de concentración y las prisiones durante la Guerra Civil y el franquismo, Barcelona, Crítica, 2003.

58. RoDRIGO, J., Los campos de concentración franquistas, Madrid, Siete Mares, 2003, y del mismo autor, aunque con la incorporación de nuevos datos, RODRIGO, J., Campos de concentración en la España franquista: 1936-1947, Barcelona, Crítica, 2005. 
que constituyeron la respuesta del franquismo al ingente problema de la acumulación de presos en la retaguardia y en los frentes, y fueron un ejemplo del deplorable estado en que se encontraban las prisiones ${ }^{59}$, y las vicisitudes de la población reclusa ${ }^{60}$.

Otra de las facetas relacionadas con la represión que ha sido objeto de atención especial por parte de los investigadores guarda relación con el exilio republicano ${ }^{61}$. En unos casos esos trabajos se engloban dentro de análisis de conjunto sobre la diáspora española contemporánea, con aportaciones tan representativas como la efectuada por el profesor Juan B. Vilar, que ha estudiado los exiliados españoles en los siglos XIX y XX, con especial hincapié a un éxodo de magnitud sin precedentes: el de la Guerra Civil de 1936-1939, sobre el que incide no sólo en protagonistas y países de destino, sino también en etapas y cifras $^{62}$. Igualmente se han publicado trabajos más específicos como el realizado por A. Alted, E. Nicolás y R. González sobre los niños que marcharon a la Unión Soviética entre los años 1937 y 1938, y donde permanecieron toda su juventud hasta 1955 en que los cambios que se produjeron en la URSS permitieron ir afrontando su repatriación ${ }^{63}$.

Del mismo modo han merecido la atención de los historiadores experiencias como la sufrida por los españoles en países de acogida como México, que desde un primer momento se mostró receptivo a la causa republicana y aceptó exilia$\operatorname{dos}^{64}$. La política de apoyo a la República por parte de ese país de Latinoamérica ha sido estudiada por J. A. Matesanz, con especial hincapié en la posición de firmeza del Gobierno de México y sus reiteradas denuncias ante la Sociedad de Naciones, sin olvidar la organización de los viajes con exiliados que llegaron a las costas mexicanas en $1939^{65}$. También sobre Francia, que había acogido a refugiados españoles desde inicios de la guerra, con oleadas posteriores tan significativas como los más de cien mil que se internaron en ese país tras la caída del Frente Norte en 1937 y, muy especialmente, las no menos nutridas expediciones tras la pérdida de Cataluña y posterior finalización del conflicto,

59. Sobre la situación del recluso en las cárceles durante el régimen de Franco, véase SERRANO, R., y Serrano, D., Toda España era un cárcel. Memoria de los presos el franquismo, Madrid, Aguilar, 2002 .

60. TORReS, R., Los esclavos de Franco, Madrid, Oberon, 2000 y LAFUENTE, I., Esclavos por la patria. La explotación de los presos bajo el franquismo, Madrid, Temas de Hoy, 2002.

61. Alted, A. y LLUISIA, M., La cultura del exilio republicano español de 1939, Madrid, UNED, 2003, 2 vols.

62. VILAR, J. B., La España del exilio. Las emigraciones politicas españolas en los siglos XIX y XX, Madrid, Síntesis, 2006.

63. Los niños de la guerra de España en la Unión Soviética (1937-1999), Madrid, Fundación Largo Caballero, 1999.

64. Segovia, R., Misión de Luis I. Rodríguez en Francia. La protección de los refugiados españoles, julio a diciembre de 1940, México, Colegio de México, Secretaría de Relaciones Exteriores y Consejo Nacional de Ciencia y Tecnología, 1999.

65. Matesanz, J. A., Las raíces del exilio. México ante la guerra civil española. 1936-1939, México, Colegio de México y Universidad Nacional Autónoma de México, 1999. 
ha sido objeto de obras generales ${ }^{66}$, y otras más específicas como la dedicada a una zona donde se establecieron muchos exiliados: Toulouse ${ }^{67}$.

Y junto a esas aportaciones globales, creemos que los avances más significativos en el análisis de la represión se han registrado en los estudios de ámbito territorial. Sería muy prolijo, dada la abundancia de obras y las limitaciones espaciales del presente artículo, abundar sobre lo publicado en los últimos años en cada Comunidad Autónoma. Afortunadamente ha sido nutrido el grupo de historiadores que se ha dedicado a analizar, pese a la precariedad de las fuentes documentales y la cada vez más notoria ausencia de testimonios orales de testigos de aquellos hechos, la magnitud de las prácticas represivas originadas por el bando franquista, no sólo la más abundante en cuanto a número de víctimas, sino también la más complicada de desentrañar debido a la carencia de vestigios para abordar esta empresa con plenas garantías. Bien se preocuparon sus autores de no dejar rastros que pudieran demostrar sus implicaciones en tamaño despropósito. Pese a ello no han faltado historiadores que han sabido rastrear ese pasado y encontrar luz donde hasta hace poco sólo había tinieblas.

Así, en Comunidades controladas desde inicios del alzamiento por las tropas sublevadas como Galicia y Castilla y León, que destacaban por la ausencia de publicaciones sobre la represión, al menos desde unos parámetros metodológicos y archivísticos acordes con lo realizado en otras zonas del país, en los últimos años han roto esa tendencia. Así, en Segovia, fruto de una tesis doctora ${ }^{68}$, se ha profundizado en las dos vertientes represivas del franquismo: las ejecuciones y prisioneros, junto a la material o económica, con unos resultados de indudable valor. También en esa provincia se han analizado contenidos tan recurrentes como las depuraciones en el sistema educativo ${ }^{69}$. Lo publicado sobre otras provincias como Valladolid ${ }^{70}$, Palencia ${ }^{71}$, Salamanca ${ }^{72}$ y León, en este último caso con una tesis doctoral de reciente lectura, muestran el auge que van

66. Dreyfus-ARmand, G., El exilio de los republicanos españoles en Francia, Barcelona, Crítica, 2000.

67. DOMergue, L. (ed.), L'exil républicain espagnol à Toulouse, 1939-1999, Toulouse, Presses Universitaires du Mirail, 1999.

68. Vega SombríA, S., Control sociopolitico e imposición ideológica: la provincia de Segovia, 1936-1939. Un episodio en la implantación del franquismo, Madrid, tesis doctoral, inédita, 2003; VEGA SOMBRÍA, S., "La represión en la provincia de Segovia en los orígenes del régimen de Franco», Hispania Nova, 4 (2004), y del mismo autor, De la esperanza a la persecución. La represión franquista en la provincia de Segovia, Barcelona, Crítica, 2005.

69. De DUEÑAS, C. y GRIMAU, L., La represión franquista de la enseñanza en Segovia, Valladolid, Ámbito, 2004.

70. MARTín JimÉnez, I., La Guerra Civil en Valladolid (1936-1939). Amaneceres ensangrentados, Valladolid, Ámbito, 2000.

71. Palomares, J. M., La Guerra Civil en Palencia: la eliminación de los contrarios, Palencia, Cálamo, 2002.

72. López García, S. y Delgado CruZ, S., "Víctimas del Nuevo Estado: 1936-1940», en MarTín, J. L. y Robledo, R. (eds.), Historia de Salamanca, vol. V (siglo XX), Salamanca, Centro de Estudios Salmantinos, 2001; y López GarCíA, S. y otros, Guerra Civil en Salamanca, Barcelona, Crítica, 2007. 
tomando este tipo de estudios en una Comunidad que había destacado hasta tiempos recientes por todo lo contrario.

En cuanto a Galicia cabe señalar que en la misma línea que la Comunidad anterior, ha sido en las dos últimas décadas cuando han ido apareciendo trabajos de interés sobre la represión en la Guerra $\mathrm{Civil}^{73}$. Y no es que con anterioridad no se hubieran publicado libros relacionados con la contienda, todo lo contrario: ha habido un ingente número de títulos, sólo que, como acertadamente ha señalado el profesor J. Aróstegui en referencia a un contexto nacional, "Es verdad que sobre la guerra española se ha dicho muchísimo; lo deplorable es, sin embargo, que la mayor parte de lo dicho carece del fundamento esencial de lo que en ciencias sociales puede considerarse aceptable (...) $\rangle^{74}$. El caso gallego es suficientemente paradigmático en ese sentido: se ha tenido que esperar a que determinados archivos abrieran sus puertas a los historiadores para que aspectos tan incardinados con el fenómeno represivo franquista como los consejos de guerra fueran estudiados y fruto de esa consulta, junto a las de otras fuentes anexas, se han publicado en los últimos años una serie de libros de indudable interés.

Uno de ellos es el realizado por el profesor de la Universidad de Vigo, Julio Prada Rodríguez, buen conocedor de la represión franquista en tierras gallegas $^{75}$, y muy especialmente en Orense ${ }^{76}$, a la que dedicó su tesis doctoral. Fruto de ello ha sido la publicación de una serie de trabajos ${ }^{77}$, en los que muestra el alcance de la violencia franquista en la provincia orensana. Otra tesis ha sido el germen de otro interesante estudio sobre Lugo, a cargo de María Jesús Souto Blanco ${ }^{78}$; Pontevedra también ha sido objeto de estudio ${ }^{79}$; y, finalmente, el esperado trabajo dedicado a La Coruña, coordinado por el profesor Emilio Grandío ${ }^{80}$, ha visto la luz con relevantes aportaciones sobre el alcance de la represión en esa provincia, que como el mismo ha recordado en otro estudio «es singular en el contexto gallego y decisiva en la estrategia del golpe militar y

73. Véase PRADA RodrígueZ, J., «Estado de la cuestión y líneas interpretativas sobre represión y franquismo", en JuANA, J. de y PRADA RodríGuez, J. (coords.), Lo que han hecho en Galicia, Barcelona, Crítica, 2006, pp. 1-17.

74. ARóstegui, J., Historia y memoria de la Guerra Civil, Valladolid, Junta de Castilla y León, 1988, v. I, p. 11.

75. Prada Rodríguez, J., Metodología e fontes para o estudio da represión franquista en Galicia, Ourense, Obradoiro de Historia de Galicia, 2003.

76. Prada RodríGUEZ, J., "Memoria «da longa noite de pedra». La represión franquista en Ourense (1936-1939)", Revista de Historia Actual-On Line, 4 (2004).

77. Prada RodríGUEZ, J., Ourense: 1936-1939. Alzamiento, guerra y represión, Sada-A Coruña, Edición do Castro, 2004, y del mismo autor, De la agitación republicana a la represión franquista. Ourense: 1934-1939, Barcelona, Ariel, 2006.

78. SOUTO BLANCO, M. J., La represión franquista en la provincia de Lugo (1936-1940), Sada, Ediciones do Castro, 1998.

79. RodríGuez Gallardo, A., "Golpe de Estado y represión franquista en la provincia de Pontevedra", en JUANA, J. de, y PRADA, J. (coords.), Lo que han hecho en Galicia. Violencia politica, represión y exilio (1936-1939), Barcelona, Crítica, 2006, pp. 135-164.

80. Grandío Seonne, E., Años de odio. Golpe, represión e guerra civil na provincia da Coruña (19361939), A Coruña, Diputación Provincial, 2007. 
su posterior represión» ${ }^{81}$. Trabajos que ponen de manifiesto las consecuencias de la violencia franquista en esta Comunidad, que marcaron a su población, como se ha demostrado en la obra coordinada por los profesores J. de Juana y J. Prada ${ }^{82}$, durante décadas.

Este mismo análisis se puede continuar con otras Comunidades ${ }^{83}$, pero consideramos que esa pretensión, aunque justificada dada la vitalidad que han adquirido los estudios sobre la represión en la Guerra Civil en los diferentes territorios de España, no se ajusta a lo exigido en este modesto artículo y se impone la necesidad de acotar. No sin antes extendernos sobre lo publicado en una Comunidad Autónoma que, aparte de conocerla bien en esta materia ${ }^{84}$, también ha vivido en los últimos años un llamativo resurgir bibliográfico sobre los efectos de la represión durante la contienda armada. Nos estamos refiriendo a Extremadura ${ }^{85}$, y especialmente a su provincia menos estudiada en esta materia: Badajoz ${ }^{86}$. Y, ciertamente, los resultados cabe calificarlos de muy positivos, pues al día de hoy sabemos que en esta Comunidad el bando republicano pasó por las armas a unas 1.600 personas y el franquista, durante la contienda y posguerra, a 14.000 de las cuales 12.000 correspondieron a Badajoz, sin duda la provincia española más castigada por los fusilamientos llevados a cabo por el bando vencedor del conflicto ${ }^{87}$. Una cifra estremecedora, que muestra la vesania empleada por el ejército, guardias civiles y, sobre todo, falangistas en tierras extremeñas.

Y el conocimiento de esos datos ha sido posible gracias a la aportación de trabajos como el de Francisco Espinosa Maestre ${ }^{88}$, buen conocedor de la guerra civil en el suroeste de España ${ }^{89}$, como ha demostrado en su obra: La columna de

81. Grandío SeoAne, E., "Golpe de Estado y represión franquista en la provincia de A Coruña: "Qué pasa con Coruña»", en JuANA, J. de, y PRADA, J. (coords.), Lo que han hecho en Galicia. Violencia politica, represión y exilio (1936-1939), Barcelona, Crítica, 2006, pp. 19-58.

82. JuANA, J. de, y PRADA, J. (coords.), Lo que han hecho en Galicia. Violencia politica, represión y exilio (1936-1939), Barcelona, Crítica, 2006.

83. Citamos a título de ejemplo dos obras sobre otras Comunidades: GIL ANDrés, C., Lejos del Frente: la guerra civil en la Rioja Alta, Barcelona, Crítica, 2006. GUTIÉRREZ FloRES, J., Guerra Civil en Cantabria y pueblos de Castilla, Editorial en Red, 2006; y del mismo autor y editorial, Víctimas en Cantabria y pueblos de Castilla-León, 2007.

84. CHAVES, J., "Historiografía sobre la guerra civil 1936-1939: Extremadura», Revista de Historia Actual-On Line, 4 (2004).

85. RIESCO ROCHE, S., La reforma agraria y los origenes de la Guerra Civil. Cuestión yuntera y radicalización patronal en la provincia de Cáceres (1931-1940), Madrid, Biblioteca Nueva, 2006.

86. Sobre Cáceres se han publicado trabajos desde hace años; véase CHAVES, J., La represión en la provincia de Cáceres durante la guerra civil, Cáceres, Universidad de Extremadura, 1995.

87. Cifra que supera con creces los 9.579 ejecutados por este bando en Córdoba y los 8.000 de Sevilla, segunda y tercera, respectivamente, en cuanto a número de fusilados por los franquistas en territorio español. SÁNCHEZ MARROYO, F., "Represión franquista y represión republicana en la Guerra Civil», en CHAVES, J. (coord.), Memoria Histórica y Guerra Civil: Represión en Extremadura, Badajoz, Diputación Provincial, 2004, pp. 39-60 (p. 60 para esta cita).

88. Contra el olvido. Historia y Memoria de la Guerra Civil, Barcelona, Crítica, 2006.

89. ESPINOSA, F., La justicia de Queipo. Violencia selectiva y terror fascista en la II División en 1936. Sevilla, Huelva, Cádiz, Córdoba, Málaga y Badajoz, Sevilla, el autor, 2000. Este mismo trabajo ha sido 
la muerte. El avance del ejército franquista de Sevilla a Badajo $z^{90}$. En su contenido analiza el paso de las tropas de Franco -Columna Madrid- por la provincia pacense desde su salida de Sevilla a primeros de agosto de 1936 hasta la ocupación de Badajoz el 14 de ese mes, junto a unas operaciones de ocupación complementarias llevadas a cabo por la parte meridional de esa provincia. De sus conclusiones se deduce que la represión practicada por ese ejército a su paso por esta provincia estuvo marcada por una brutal crueldad, que acabó con la vida de un ingente número de personas. Un trabajo, pues, de referencia que constituye una aportación de indudable valor para el conocimiento de la represión.

Y también en la provincia pacense se sitúa el estudio de José Luis Gutiérrez Casalá, La Guerra Civil en la provincia de Badajoz. Represión republicano-franquis$t a^{91}$. Un historiador que ya había dado muestras de manejar una novedosa documentación en obras pretéritas ${ }^{92}$, que en ésta profundiza en aspectos diversos relacionados con el fenómeno represivo, entre los que destacamos los efectos que tuvo en Badajoz la sistemática utilización de los consejos de guerra y las sentencia a pena capital que acabaron con la vida de 1.109 personas. No obstante, este autor ofrece un balance de víctimas a causa de la guerra civil en Badajoz que consideramos equivocado, al dar unas cifras en lo referente a la represión franquista desproporcionadas e imprecisas, necesitadas de revisión para no introducir más confusión en el siempre complicado empeño de ofrecer balances definitivos.

Y directamente relacionados con el proyecto Recuperación de la Memoria Histórica que se viene desarrollando en esta Comunidad gracias al apoyo de la Consejería de Cultura de la Junta de Extremadura y las Diputaciones Provinciales de Cáceres y Badajoz junto a la Universidad de Extremadura, se han ido publicando en los últimos años una serie de trabajos coordinados por el autor de este artículo, que estimamos de interés. El primero de ellos tiene como título Política científica y exilio en la España de Franco ${ }^{93}$, publicación que se articula en torno a tres ejes que consideramos indispensables en cualquier trabajo de estas características: fuentes para el estudio de los exiliados españoles tras la Guerra Civil; dinámica represiva practicada por el franquismo en el transcurso del conflicto armado de 1936-1939 y con posterioridad, y, finalmente, reseñas biográficas sobre exiliados.

La segunda publicación se denomina: Memoria Histórica y Guerra Civil: Represión en Extremadura ${ }^{94}$, que presenta como novedad contar con la participación de la mayoría de los especialistas extremeños en esta materia y aportar estudios

objeto de una segunda edición corregida, revisada y ampliada, publicada por Crítica (2006), con la colaboración de la Junta de Extremadura.

90. Barcelona, Crítica, 2003.

91. Badajoz, Universitas, 2003, y del mismo autor, La guerra Civil en la provincia de Badajoz. Segunda parte, Badajoz, Universitas, 2005.

92. Gutiérrez Casalá, J. L., Las Colonias Penitenciarias de Montijo, Mérida, Editora Regional de Extremadura, 2002.

93. Badajoz, Universidad de Extremadura, 2002.

94. Badajoz, Diputación Provincial, 2004. 
locales y provinciales de diferente valor y consideración, que en su conjunto constituyen un recorrido interesante sobre la situación en que se encuentran las investigaciones sobre la contienda en esta Comunidad. Y en la misma línea de trabajo cabe situar Historia y Memoria de la Guerra Civil en Extremadura: Badajoz en agosto de $1936^{95}$. Obra de conjunto, en la que aparte de las referencias a cuestiones de ámbito nacional efectuadas por reputados especialistas (P. Preston, H. Raguer), se profundiza sobre lo sucedido en Badajoz por parte de investigadores que ofrecen sus últimos estudios sobre aspectos represivos relacionados con la capital y provincia pacense, que confirman la cifra de 12.000 fusilados por el franquismo en todo su ámbito territorial.

Y no sólo ejecuciones, las prisiones también han merecido la atención de investigadores universitarios como Antonio López Rodríguez, que ha estudiado de forma pormenorizada las devastadoras consecuencias que tuvo entre la población republicana uno de los centros de reclusión de más funesto recuerdo en toda España: el campo de concentración de Castuera ${ }^{96}$. La muerte tuvo un notable protagonismo tanto en el interior como en el extrarradio de este funesto recinto penitenciario, con frecuentes sacas de prisioneros y vejaciones incalificables sobre la población reclusa, según se demuestra en este interesante trabajo.

Obras, por tanto, que ponen en evidencia el esfuerzo que se está realizando en esta Comunidad Autónoma por dar a conocer las consecuencias represivas de la Guerra Civil, labor que creemos es trasladable a buena parte de España. Ello, sin embargo, no debe hacernos olvidar que aún queda bastante camino por recorrer en aspectos como los totales de óbitos por acciones represivas, pues si bien en muchas provincias se conocen, otras, sin embargo, no cuentan con esos datos. Es preciso ir cerrando este apartado para que el mapa de las "cifras» se pueda dar por ultimado y poder establecer balances fiables sobre el alcance de la represión por ese concepto. Estamos convencidos de que con ello concluirá un importante capítulo de la Guerra Civil, sin duda el más delicado y controvertido, aunque, evidentemente, no el único.

\section{MOVIMIENTOS DE RECUPERACIÓN DE LA MEMORIA HISTÓRICA}

Y todo ejercicio bibliográfico sobre la represión en la Guerra Civil, especialmente la practicada por el bando de Franco durante la contienda y con posterioridad, quedaría huérfano si no se hace referencia a un movimiento social que en los últimos años ha acaparado, creemos que con derecho propio, un lugar estelar en el conocimiento y difusión de esos años de contienda. Nos estamos refiriendo a la iniciativa fomentada por asociaciones que pretenden dignificar el recuerdo de los represaliados por el franquismo, y que es conocida, de forma genérica, como Recuperación de la Memoria Histórica. Un movimiento que ha

95. Badajoz, Diputación Provincial, 2006.

96. LóPez RODRíguez, A., Cruz, bandera y castillo: el campo de concentración de Castuera, Badajoz, CEDER La Serena, 2007. 
tenido una repercusión social inequívoca en toda España, que ha merecido la atención de las instituciones, hasta el punto de que el ejecutivo socialista presidido por José Luis Rodríguez Zapatero ha llevado al Parlamento un proyecto de Ley que pretende dar respuesta a esa demanda social.

Pero hasta llegar a ese punto ${ }^{97}$, las políticas de la memoria en España relacionadas con ese pasado histórico desde inicios del milenio creemos que han tenido un protagonismo al que los historiadores no debemos ser ajenos ${ }^{98}$. Y es que resuelta la cuestión del acceso a los archivos y obviando, por no tener solución, la contingencia originada por la prolija información que se hizo desaparecer, al iniciarse el siglo XXI el debate sobre la documentación relacionada con la Guerra Civil se sitúa en otros parámetros: la España de las Autonomías. Cuestiones como al traspaso al Gobierno de la Generalitat de Cataluña de su documentación sobre la Guerra Civil han acaparado buena parte de la atención sobre esta materia. Una documentación que fue incautada por el régimen de Franco y trasladada a un archivo estatal en Salamanca como depósito de documentos con evidentes finalidades represivas, que durante la Transición pasó a depender del Archivo Histórico Nacional, Sección de la Guerra Civil, y en 1999, con el Gobierno del Partido Popular, se creó el Archivo General de la Guerra Civil Española en Salamanca.

Esta última disposición daba solidez a la unidad de archivo allí creada y protegía legalmente sus documentos frente a las reivindicaciones de Cataluña y otras Comunidades Autónomas. Un paso significativo, sin duda, por lo que suponía de asentar la tesis de los que defienden que en Salamanca debe permanecer toda la información original allí depositada "como símbolo de la definitiva terminación de la Guerra civil en la conciencia de los españoles»"99. Frente a éstos, los que se escudan en el argumento de que los documentos deben devolverse a sus legítimos propietarios y que no se puede perpetuar esa expoliación política como signo de reconciliación, pues como indica el profesor Borja de Riquer, "se hace un mal servicio a la democracia si se mantienen, con el pretexto de una supuesta superación de la contienda, los actos violentos y las disposiciones represivas de la dictadura franquista» ${ }^{100}$.

Una «Comisión de Notables», a instancias del ejecutivo, se encargó de debatir esta espinosa cuestión, y al iniciarse el año 2005 hizo público su dictamen: los documentos originales debían ser enviados a Cataluña. Decisión que se ha llevado a efecto tras dejar en el Archivo de Salamanca la correspondiente copia y un reguero de declaraciones y protestas poco aleccionadoras, en el que destacamos un desencuentro entre Comunidades Autónomas poco edificante, del que se desprende que deben crearse, dentro de un consenso lo más amplio posible, elementos regulativos que normalicen este tipo de demandas que lejos

97. Aguilar, P., Memoria y olvido de la guerra civil, Madrid, Alianza, 1996.

98. SilVA, E.; ESTEBAN, A.; CASTÁN, J. y SALVADOR, P. (coords.), La memoria de los olvidados, Valladolid, Ámbito, 2004.

99. SCHWARTZ, P., "El Archivo de Salamanca», La Vanguardia, 2-VI-2004.

100. De Riquer, B., "A propósito del Archivo de Salamanca", La Vanguardia, 7-VI-2004. 
de restañar «injusticias históricas», sólo sirven para alentar enfrentamientos. Y tras haber pasado tanto tiempo desde la terminación de la Guerra Civil, si algo resulta impertinente y poco aleccionador en la España actual es generar conflictos por cuestiones inherentes a ese conflicto armado, que pueden ser solucionadas adecuadamente en el actual marco de un Estado de derecho democrático y plural.

Consideramos que los historiadores no podemos permanecer ajenos a este tipo de controversias que afectan a todos los españoles y evidencian que aún perduran en la España del siglo XXI los efectos del conflicto armado de 19361939 y de la sistemática política de olvido y desmemoria llevada a cabo por los vencedores. Y es en ese escenario donde cabe ubicar la labor llevada a cabo por "recuperar la memoria histórica", protagonizada por una serie de colectivos que hunden sus raíces en los años de democracia. Asociaciones que en nuestra opinión han supuesto un importante revulsivo para estimular la conciencia ciudadana acerca de las consecuencias que esa implacable labor represiva sobre la población disidente, tanto en la guerra como en los años de dictadura, y el deliberado olvido de que fueron objeto esas víctimas.

En la actualidad existe en España un número importante de asociaciones que demandan dignidad y reconocimiento para los vencidos en la Guerra Civil. Citarlas a todas sería muy prolijo, aunque todas sin excepción merecen un lugar destacado en el desarrollo de su actividad. Sin embargo, pese al riesgo inherente a cualquier tipo de distinción, deseamos resaltar tres que por diversas razones conocemos desde sus orígenes y creemos que se han convertido en referencia inevitable cuando se hace mención a estas cuestiones dentro del Estado español.

Una de ellas, la más veterana, es la Asociación Archivo Guerra y Exilio (www. nodo50.org), que ha llevado a cabo importantes proyectos y actos con vistas a conseguir «El reconocimiento y dignificación de las víctimas del franquismo que la Transición dejó ad limina, en la puerta del olvido» (Cabra, 2003, 139144). Especialmente pertinente ha sido su labor con vistas a homenajear el movimiento de oposición armada al franquismo de los años cuarenta, con la presencia de guerrilleros en cada uno de sus actos. También en su evocación de la participación en la Guerra Civil de las Brigadas Internacionales, con una inolvidable Caravana de la Memoria que visitó diferentes Comunidades Autónomas españolas en el otoño de 2000, compuesta por brigadistas, exiliados, niños de la guerra y guerrilleros. Por último destacar su infatigable labor ante los poderes públicos, con la consecución de ayudas tan significativas como poder investigar en archivos tan emblemáticos y desconocidos en el estudio de la Guerra Civil como el del Partido Comunista de España en Moscú (Rusia) o iniciativas tan señeras en el objetivo de conseguir el reconocimiento y la memoria de los vencidos, y especialmente de los guerrilleros que lucharon contra el franquismo en la posguerra, con actos tan emotivos como llevar a los pocos protagonistas que viven en la actualidad y son miembros de la asociación al Parlamento español para que los diputados conocieran sus demandas y reivindicaciones directamente. 
Otro de esos colectivos es Gavilla Verde (www.lagavillaverde.org), que se presenta como «una asociación de desarrollo rural y sostenible que trabaja en el terreno de la recuperación de la memoria histórica por la importancia que el período guerrillero de los años cuarenta tuvo en la Serranía de Cuenca, Teruel y Valencia» (Peinado, 2003, 2). Anualmente celebran unas jornadas en la emblemática población conquense de Santa Cruz de Moya con el sugerente título, Crónica Rural de la Guerrilla Española. Memoria Histórica Viva. Un evento interdisciplinar que añade a las necesarias referencias históricas contenidos tan sugerentes como la literatura, el cine, la fotografía, la escultura y el documental. Todo ello con la presencia de protagonistas de la Guerra Civil y del movimiento de oposición armada al franquismo de los años cuarenta, que exponen sus testimonios. Del mismo modo, esta población se ha convertido en un lugar de homenaje y reconocimiento a ese movimiento, hasta el punto de haber erigido un monumento al guerrillero que se ha convertido en un lugar de encuentro y reivindicación.

Finalmente es preciso resaltar la labor del colectivo Asociación para la Recuperación de la Memoria Histórica (www.memoriahistorica.org), de fundación más reciente que los dos colectivos anteriores (año 2000), que ha desarrollado una intensa labor en la búsqueda de los fusilados por el bando de Franco durante la Guerra Civil. Fruto de ello ha sido el hallazgo de numerosas fosas con los cuerpos de las personas ejecutadas a lo largo y ancho de la geografía nacional, en las que actúan mediante la organización de campos de trabajo a través de los que proceden a exhumar los restos $y$, de conformidad con los familiares de los afectados, proceden a darles un enterramiento digno ${ }^{101}$. Para el desarrollo de esa labor cuentan con la colaboración de forenses, arqueólogos y otros especialistas. Han creado asociaciones filiales en todas las Comunidades Autónomas españolas, de forma que su mensaje se ha extendido por todo el país, de forma que bien en colaboración o siguiendo sus instrucciones han procedido a desarrollar ese trabajo de localización y exhumación de fosas. Sus acciones para el reconocimiento de estas víctimas originadas por la represión franquista no se han limitado a instancias políticas nacionales, sino que han llegado hasta la Organización de Naciones Unidas ${ }^{102}$.

Sectores importantes de la juventud, muchos de ellos universitarios, nacidos y criados en democracia (hijos de la democracia española), han mostrado su deseo de participar en estos movimientos asociativos y se han convertido en uno de sus principales sustentos. Es importante subrayar este aspecto, pues hace unos años era impensable en España gozar de un contexto social en el que los jóvenes mostraran su deseo por conocer lo sucedido en la Guerra Civil, y ahora ocurre todo lo contrario: no sólo se interesan, sino que participan activamente en actos relacionados con ese período. Del mismo modo, las nuevas tecnologías han

101. Armengou, M., y Belis, R., Las fosas del silencio, Barcelona, Plaza \& Janés, 2004.

102. SilVA, E. y MACíAS, S., Las fosas de Franco. Los republicanos que el dictador dejó en las cunetas, Madrid, Temas de Hoy, 2003, pp. 101 y ss. 
permitido un acercamiento inmediato a estas asociaciones, con algunas específicas que han creado su propia web en la que ofrecen colaboración a aquellos que tratan de encontrar a familiares desaparecidos durante la Guerra Civil y el franquismo. La demanda de personas que buscan ese tipo de información ha sido ingente ${ }^{103}$, y ha exigido una respuesta social en la que se han implicado claramente determinadas instituciones públicas españolas, con el apoyo a proyectos de investigación que abunden en la identificación de los "desaparecidos» a causa de las medidas represivas franquistas y la correspondiente exhumación de fosas, previa conformidad de los familiares de los afectados.

En definitiva, si bien la investigación histórica ha sido y es importante, no lo es menos el movimiento ciudadano e institucional que ha acompañado este proceso en los últimos años, que amparado en asociaciones y colectivos han sabido crear el ambiente necesario para que sus demandas se vean correspondidas por medidas políticas tan significativas y polémicas como la futura "Ley de la memoria histórica». Pero independientemente de la viabilidad y falta de consenso político sobre este texto legal, lo cierto es que en España se ha iniciado un camino que consideramos no tiene vuelta atrás con vistas a reconocer a las víctimas de la Guerra Civil y la dictadura de Franco. Un escenario novedoso y de indudable interés que permitirá llevar a cabo actuaciones que, lejos de reabrir viejas heridas, estamos convencidos que ayudará a cicatrizarlas y a consolidar la convivencia entre los españoles.

103. Armengou, M. y Belis, R., Las fosas del silencio, Barcelona, Plaza \& Janés, 2004, pp. 241 y ss. 